\title{
Mudanças na exposição da população à fumaça gerada por incêndios florestais na Amazônia: o que dizem os dados sobre desastres e qualidade do ar?
}

\author{
Changes in the population's exposure to smoke generated by forest fires \\ in the Amazon: what do the data on disasters and air quality say?
}

Liana Anderson', Victor Marchezini1

DOI: 10.1590/0103-11042020E220

RESUMO O uso do fogo e seus impactos são crescentes na Amazônia. Neste estudo, avaliou-se a problemática das queimadas e incêndios florestais no contexto da proteção e defesa civil objetivando avaliar o número de registros de situação de emergência ou estado de calamidade pública declarados ante o aumento da ocorrência de queimadas e incêndios florestais na Amazônia. Fez-se uma análise histórica para quantificar mudança na exposição da população a queimadas, incêndios florestais e qualidade do ar. Em seguida, uma visão da crise dos incêndios florestais na Amazônia em 2019, em que um dos principais impactos imediatos foi baixa qualidade do ar associada a esses eventos é apresentada. As análises sugerem que existe um negligenciamento em registrar oficialmente situações de emergência e calamidade pública associados à baixa qualidade do ar, oriundos de queimadas e incêndios florestais, principalmente na região norte do País. Mediante acompanhamento da crise entre os meses de julho e agosto de 2019, devido à situação crítica da ocorrência de queimadas e incêndios florestais reportados até o final de 2019 no sudoeste da Amazônia, entende-se que há possibilidade desse quadro ser considerado um desastre.

PALAVRAS-CHAVE Incêndios florestais. Vulnerabilidade. Desastres.

\begin{abstract}
The fire use and its impacts are growing in the Amazon. In this study, the problem of burning and wildfires in the context of civil protection and defense was evaluated, to assess the number of records of emergency situations or state of public calamity declared regarding the increase in the occurrence of fires and forest fires in the Amazon. A historical analysis was carried out to quantify changes in the population's exposure to fires, forest fires and air quality. A vision of the forest fire crisis in the Amazon in 2019 was presented in which one of the main immediate impacts was low air quality associated with these events. The analyzes suggest that there is a neglect in officially registering emergency situations and public calamities associated with low air quality, arising from burnings and forest fires, mainly in the northern region of the country. Through the monitoring of the crisis between the months of July and August 2019, due to the critical situation of the occurrence of fires reported until the end of 2019 in the southwest of the Amazon, it is understood that there is a possibility that this situation could be considered a disaster.
\end{abstract}

1 Centro Nacional de Monitoramento e Alertas de Desastres Naturais (Cemaden) - São José dos Campos (SP), Brasil. liana.anderson@cemaden. org.br
KEYWORDS Wildfires. Vulnerability. Disasters. 


\section{Introdução}

A cada ano, 4 milhões de pessoas morrem devido à poluição do ar em áreas abertas, em consequência das partículas finas - com diâmetro de 2.5 micrômetros ou menos (PM2.5) - que penetram nos pulmões, coração e corrente sanguínea, onde causam doenças e alguns tipos de câncer. Um artigo publicado recentemente na revista 'Nature' demonstrou que essas partículas se formam a partir de compostos e toxicidades diferentes, que variam de lugar para lugar e ao longo

do tempo ${ }^{1}$, sendo necessário compreender essas ameaças, sua intensidade, frequência, magnitude, para, a partir disso, formular medidas que ajudem a diminuir a exposição das pessoas e, assim, atenuar impactos na saúde pública. A concentração dessas partículas pode se tornar uma fonte de ameaças e/ou perigo, isto é, um processo, fenômeno e/ou atividade humana que pode ocasionar algum potencial de dano, perda e impacto ${ }^{2}$.

Especialistas em saúde pública têm estudado algumas dessas ameaças relacionadas com a qualidade do ar, como os impactos de queimadas e as doenças respiratórias em diferentes grupos sociais e regiões do Brasil ${ }^{3-5}$. Com exceção dos grandes centros urbanos, em que a qualidade do ar é mais fortemente influenciada pela poluição gerada localmente por veículos 6 , na maioria do extenso território brasileiro, as queimadas e incêndios florestais são os fatores que mais contribuem para a poluição atmosférica com impactos para a saúde7. Um relatório recente do Banco Mundial identificou que o Brasil está entre os quatro países do mundo que mais utilizam o fogo para a queima de resíduos agrícolas ${ }^{8}$. Estudos também indicam que existe uma forte relação entre anos de secas extremas e impactos na saúde devido à ocorrência de queimadas e incêndios florestais, como em anos de El Niño ${ }^{9}$. Na Amazônia, anos de secas extremas, como em 1997/98, 2005, 2010, $2015 / 16$, foram marcados por grandes incêndios florestais ${ }^{10-13}$. Além disso, em anos com altas taxas de desmatamento na Amazônia, há um aumento de até duas vezes mais particulados na atmosfera oriundos de queimadas e incêndios florestais, em comparação com anos com baixas taxas de desmatamento ${ }^{7}$.

Entretanto, os impactos na saúde devido a queimadas e incêndios florestais não têm sido tratados, do ponto de vista do Sistema Nacional de Proteção e Defesa Civil (Sinpdec), como um desastre, o que permitiria, por conseguinte, criar políticas públicas e fortalecer ações para redução do risco de eventos associados a esses processos, de forma a mitigá-los. Compreende-se por desastre danos e perdas que excedem a capacidade local de fazer frente à situação ${ }^{\mathbf{1 4}}$.

Dessa forma, este artigo abordará essa questão a partir da análise dos dados do Sistema de Informações sobre Desastres (S2ID) visando identificar os registros de ocorrências de situações de desastres associados a queimadas e incêndios florestais, focos de calor, como uma proxy para queimadas e incêndios florestais, dados de qualidade do ar referentes aos níveis de concentração de PM2.5, e dados populacionais, visando quantificar espacialmente não só o aumento de ignições, mas também a exposição das pessoas a proximidade desses eventos. Evidenciaremos as análises para o Acre, onde, em 2018, foi quantificado o pico histórico de desmatamento no estado, culminando com a determinação da compra de sensores para o monitoramento da qualidade do ar no início de 2019, feita pelo Ministério Público ${ }^{15}$. Segundo dados atuais do projeto 'Monitoramento do Desmatamento da Floresta Amazônica Brasileira por Satélite' (Prodes/Inpe), que fornece as estimativas oficiais do País, em 2019, houve um novo recorde histórico do total de áreas desmatadas no estado do Acre.

Este artigo, portanto, busca analisar condições de exposição à fumaça gerada por queimadas com a finalidade principal de subsidiar a política pública de gestão de emergências associadas às condições 
de particulados na atmosfera, oriundos de queimadas e incêndios florestais. Inicialmente, apresentamos os conceitos principais e uma visão geral sobre a problemática das queimadas e incêndios no contexto da proteção e defesa civil. A partir da base de dados S2ID, faz-se um breve histórico de registros de ocorrências de incêndios e das portarias de Situação de Emergência (SE) e Estado de Calamidade Pública (ECP) de desastres associados a incêndios florestais no estado do Acre. Após essa avaliação, analisa-se a exposição da população, entre os anos de 1998 e 2016, em áreas com ocorrência de focos de calor e as alterações no número de pessoas expostas à baixa qualidade do ar. Finalmente, é realizada uma análise focada no ano de 2019, devido à situação de queimadas e de incêndios florestais que foram reportadas na mídia nacional e internacional, levando a uma crise política no País.

No dia 23 de agosto de 2019, o presidente decretou a Garantia da Lei e da Ordem Ambiental (Gloa), que permitiu o uso das Forças Armadas para fins de ações preventivas e repressivas contra delitos ambientais, neste caso, as queimadas e os incêndios florestais, com um custo de cerca de $\mathrm{R} \$ 1,5$ milhão por dia $^{16}$. Em seguida, no dia 28 de agosto, foi decretada a proibição do uso do fogo em todo País por 60 dias (Decreto $\mathrm{n}^{\circ}$ 9.992, de 28 de agosto de 2019). Esse diagnóstico em tempo quase-real visa prover um marco da situação do Brasil entre abril e agosto de 2019. Por fim, apresentamos as conclusões e recomendações para futuros estudos.

\section{Visão geral das queimadas e incêndios no contexto da proteção e defesa civil}

Queimadas e incêndios florestais são um tipo de ameaça ou perigo complexo. Queimadas referem-se às atividades que utilizam o fogo de forma controlada, por exemplo, para o manejo do uso da terra. Denominam-se incêndios florestais, ou incêndios da vegetação, a perda de controle sobre o processo de queima, ou quando há um processo de ignição natural em que o fogo se alastra.

A partir de análises da distribuição espaço-temporal das queimadas e internações por doenças respiratórias em menores de cinco anos de idade em Rondônia, entre os anos de 2001 e 2010, foi demonstrado que localidades com maior número de focos de queimadas diferiram daquelas com as taxas mais elevadas de internações por doenças respiratórias, identificando a importância do transporte material particulado em longas distâncias na Amazônia4. No referido estudo, os focos de queimada se concentravam no noroeste do estado, enquanto as maiores taxas de internação estavam no centro e sudeste. Situação semelhante é vivenciada no estado do Acre durante as queimadas e incêndios florestais do ano 2019, em que, além da fumaça gerada pelas queimas locais, o processo de circulação atmosférica levou para a região os materiais particulados gerados em outros locais, expandindo-se ainda para afetar os países vizinhos e outras regiões do Brasil (figura 1). 
Figura 1. Identificação de focos de fogo ativo e dispersão de particulados na atmosfera devido a queimadas e incêndios florestais para o dia 6 de agosto de 2019, visualizado em uma Imagem do sensor Modis, a bordo do satélite Terra

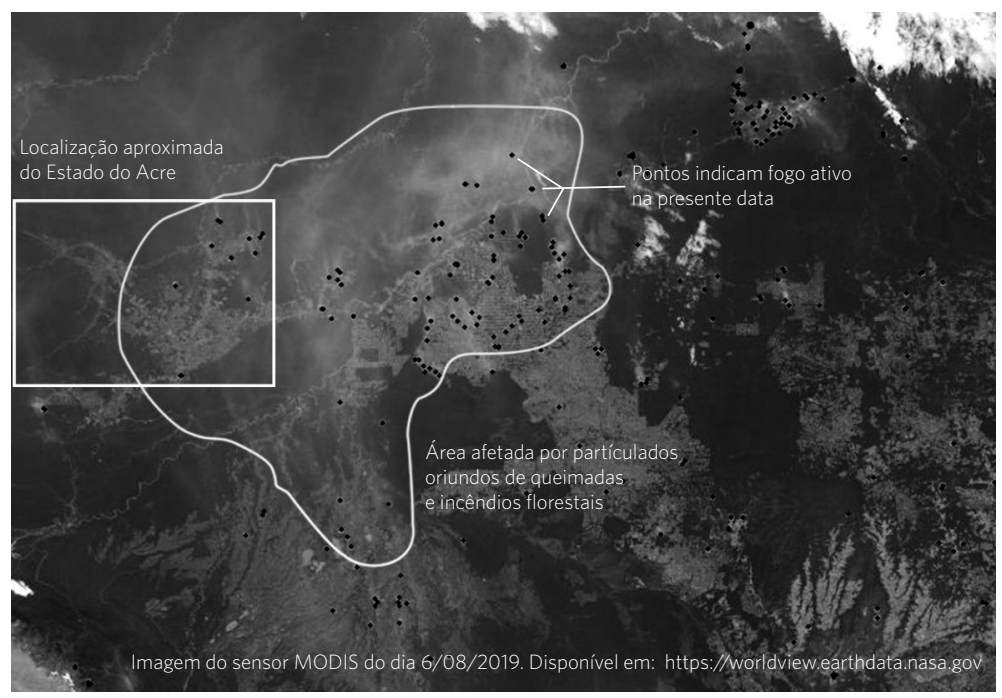

Fonte: Elaboração própria baseada na imagem do sensor Modis ${ }^{17}$.

Se do ponto de vista político-administrativo o estado do Acre se situa na região de fronteira conhecida como 'MAP', com a província de Madre de Dios (Bolívia) e de Pando (Peru), a vivência das queimadas e dos incêndios relativiza a noção de fronteira. As fumaças das queimadas e incêndios florestais são carregadas pelos ventos, sendo difícil precisar as áreas a serem atingidas, como se tem feito, por exemplo, nos mapeamentos de unidades de saúde em áreas suscetíveis a inundações e deslizamentos ${ }^{\mathbf{1 8}}$. Assim, as incertezas em dados modelados de previsão de aumento de poluentes na atmosfera que possam subsidiar ações de planejamento e preparação por parte dos sistemas de saúde a fim de atender um aumento da demanda de serviços pela população são um fator limitante. No entanto, estudos que utilizam bases históricas de dados, a fim de detectar áreas mais susceptíveis a ocorrência de baixos níveis na qualidade do ar, tornam-se uma informação-chave para o entendimento dos processos e identificação de áreas prioritárias.
As pessoas podem estar expostas a ameaças de queimadas e incêndios florestais. Entretanto, essas condições de exposição não são as mesmas, assim como as capacidades de se proteger. Alguns grupos sociais podem vivenciar situações que os tornam mais propensos a sofrerem danos e perdas em razão de suas condições sociais e meios de vida, do seu acesso a recursos econômicos, sociais, poder político, da sua capacidade física e mental de autoproteção, isto é, apresentam maior vulnerabilidade ${ }^{19}$ diante de ameaças e/ou perigos como incêndios florestais. No caso da distribuição espaço-temporal das queimadas e internações por doenças respiratórias em Rondônia entre 2001 e 2010, considerou-se um grupo com maior vulnerabilidade em relação a outros, no caso, crianças menores de cinco anos de idade 4 . Ameaça (queimada, incêndios, material particulado) e vulnerabilidade (crianças menores de cinco anos de idade por exemplo) contribuem para a configuração do risco de desastre, isto é, da probabilidade de ocorrência de perdas, 
danos e impactos que excedem a capacidade local de fazer frente à situação.

$\mathrm{O}$ risco de desastre se compreende a partir dessa conjugação entre ameaça(s) - com sua intensidade, frequência, magnitude etc., as vulnerabilidades expressas em dada organização territorial (pessoas expostas e em condições pobreza, isolamento social, desnutrição, falta de acesso à saúde, a saneamento básico etc.), ou mesmo as condições do meio físico que as cercam, a capacidade de autoproteção e as políticas públicas de mitigação para reduzir as ameaças e as vulnerabilidades ${ }^{\mathbf{2 0}}$. As capacidades de autoproteção se referem ao acesso aos recursos materiais e imateriais para se proteger diante de queimadas e incêndios florestais, como ter acesso à informação sobre essas ameaças, entendimento de suas vulnerabilidades, participação de simulados e de brigadas comunitárias de combate a incêndios etc. As políticas públicas são fundamentais para aumentar essa capacidade de autoproteção. Essas políticas de mitigação de riscos podem ser de caráter estrutural e não estrutural. Ações estruturais envolvem melhoramento de infraestruturas existentes como, por exemplo, de abastecimento de água que possa ser acionado em caso de incêndios florestais, de maquinário que permita a execução de aceiros para evitar a propagação das queimadas, de unidades de saúde capazes de lidar com emergências, aumento da capacidade das secretarias municipais e estaduais de meio ambiente, fortalecimento dos comitês de meio ambiente etc. Atividades mitigatórias não estruturais envolvem a preparação de brigadas comunitárias de combate a incêndios, efetivação e fortalecimento do cumprimento da legislação ambiental, realização de simulados, organização de campanhas educativas, criação de sistemas de monitoramento e alerta, melhoria na comunicação entre órgãos que tratam desta temática etc.

Uma forma de minimizar o risco de um desastre é a constituição de sistemas de monitoramento e alerta que pode auxiliar, por exemplo, a reduzir a exposição das pessoas às fontes de ameaça e/ou perigo, provendo informações que permitam planejar, por exemplo, a evacuação de pessoas e/ou animais em áreas a serem impactadas pelo fogo e/ou fumaça. Esses sistemas referem-se a um conjunto de capacidades e informações necessárias que permitem tomar ações antecipadas a fim de reduzir as perdas materiais, ambientais e humanas, isto é, de diminuir a probabilidade de um desastre ${ }^{21,22}$.

A percepção do tipo de ameaça/perigo e/ ou de risco de desastre a ser alertado depende de como as sociedades e governos lhes representam, toleram, isto é, o debate em torno dos riscos é influenciado pelas ideologias, pela cultura, liberdade de imprensa em diferentes períodos históricos ${ }^{20}$. No Brasil, por exemplo, a proteção e defesa civil que hoje conhecemos surgiu no contexto da Segunda Guerra Mundial, sob o nome de defesa passiva antiaérea, com a missão de alertar os civis, por meio de sirenes, e proteger sua evacuação para os abrigos subterrâneos diante dos bombardeios aéreos. A missão de salvar vidas ante os ataques aéreos alterou-se com o tempo, focando-se em outras ameaças ou perigos como inundações, deslizamentos, colapso de barragens, secas e outros eventos tipificados na Classificação e Codificação Brasileira de Desastres (Cobrade), adotada em 2012. Incêndios florestais também são um tipo de ameaça reconhecido oficialmente pela Cobrade.

Na Cobrade, os incêndios florestais são classificados como desastre, no âmbito do grupo climatológico, junto com as secas, estiagens e baixa umidade do ar. No caso dos incêndios florestais, existem duas tipificações na Cobrade: Incêndios em Parques, Áreas de Proteção Ambiental e Áreas de Preservação Permanente Nacionais, Estaduais ou Municipais (Cobrade 1.4.1.3.1) e Incêndios em áreas não protegidas, com reflexos na qualidade do ar (Cobrade 1.4.1.3.2). Um ponto interessante dessa classificação é que parece excluir o entendimento de que incêndios em áreas protegidas - que em muitos casos permite a presença de populações habitando a área, conforme prevê o Sistema 
Nacional de Unidades de Conservação (SNUC - Lei no 9.985/2000) - não necessariamente refletem impactos na qualidade do ar, tanto local quanto regionalmente. Do ponto de vista legal, os desastres são reconhecidos oficialmente no Sinpdec, quando há o reconhecimento federal de SE ou ECP. SE é o reconhecimento (legal) pelo poder público de situação anormal, provocada por desastres, causando danos superáveis (suportáveis) pela comunidade afetada. Já o ECP é o reconhecimento (legal) pelo poder público de situação anormal, provocada por desastres, causando sérios danos à comunidade afetada, inclusive à incolumidade ou à vida de seus integrantes ${ }^{23}$. No período 20032017, o governo federal reconheceu 30.913 portarias de SE ou ECP no Brasil, sendo que $41(0,13 \%)$ delas envolvem a tipificação de incêndios florestais.

A se julgar a problemática a partir do número de portarias de SE e ECP no período, poder-se-ia inferir que o risco de um desastre associado a queimadas e incêndios florestais é baixo ou, ainda, que os impactos registrados não são significativos a ponto de justificar o reconhecimento de uma SE ou ECP. Do ponto de vista científico, também se poderia questionar os bancos de dados, a subnotificação, questões políticas ou de governança, a adoção de outros métodos e abordagens para produzir maior conhecimento sobre o tema.

\section{Material e métodos}

\section{Registros de ocorrências}

Para a análise dos registros de ocorrências de incêndios e das portarias de reconhecimento de SE e ECP associadas a incêndios florestais, foram consultadas as bases de dados do S2ID, do SINPDEC. Registro se refere à inserção no S2ID de ocorrência relacionada com incêndios, sem que necessariamente tenham sido verificados danos e perdas capazes de caracterizar um desastre para, a partir disso, pleitear-se a declaração de SE e ECP. Em relação aos registros de ocorrências, o período analisado foi de 2000 a 23 de agosto de 2019. No caso das portarias de SE e ECP (desastres reconhecidos), o período disponível para análise foi de 2003 a 2017. Essa base foi consultada para ter uma análise histórica de como a problemática dos dados de incêndios se revela para o Sinpdec, na escala nacional.

\section{Exposição da população à ocorrência de queimadas e incêndios florestais e baixa qualidade do ar}

Esta avaliação foi realizada utilizando-se como área de estudo o estado do Acre. Foram empregadas três fontes de dados espaciais. A primeira refere-se à contagem da população em uma grade de aproximadamente $1 \mathrm{~km}^{2}$. A segunda base de dados, também disponibilizada em uma grade de aproximadamente $1 \mathrm{~km}^{2}$, refere-se à concentração média anual de aerossóis com particulados PM 2.5, que impactam a saúde. Finalmente, a terceira base de dados corresponde à ocorrência de focos de calor, que detectam fogo ativo, sendo uma proxy tanto para ignição do fogo como proximidade com eventos de queimadas e incêndios florestais. Esses dados são pontuais, e apresentam as coordenadas geográficas de sua ocorrência.

\section{GRADE POPULACIONAL}

A base de dados é denominada Gridded Population of the World (GPW), e encontra-se em sua versão 4, revisão 11 (GPWv4.11). O dado utilizado denomina-se Population Count $\mathrm{v} 4.11 \mathrm{e}$ fornece estimativas da contagem populacional para os anos de 2000 a 2020 , a cada cinco anos, consistentes com o censo nacional, disponibilizados em formato matricial (raster) georreferenciado, a fim de facilitar a integração com outras bases de dados ${ }^{24}$. Esse dado foi utilizado como uma aproximação para o cálculo da exposição da população acreana para queimadas e incêndios, sendo este último considerado um dos aspectos de 
sua vulnerabilidade às potenciais ameaças que queimadas e incêndios florestais implicam. O período selecionado foi de 2000 a 2015 . Os dados foram recortados para o limite do estado do Acre, e somente células com uma contagem de população maior do que zero foram utilizadas nas análises.

\section{DADOS DE QUALIDADE DO AR}

A base de dados utilizada denomina-se Global Annual PM2.5 Grids from Modis, MISR and SeaWiFS Aerosol Optical Depth (AOD) - GWR, v1, disponibilizada em uma grade matricial com aproximadamente $1 \mathrm{~km}^{2}$ de resolução espacial, e resolução temporal de um ano, recobrindo o período de 1998 a $2016^{25}$. Os dados foram processados de forma a identificar os anos que tiveram a média de aerossol acima do limiar de PM 2.5, e a recorrência de anos foi calculada de forma a identificar as regiões mais críticas em que a população ficou exposta a riscos de doenças respiratórias devido às condições de aerossóis oriundos de queimadas e incêndios. Baseando-se nas áreas de maior recorrência, calculamos o aumento do número de pessoas nas áreas em que foram observadas maiores recorrências de exposição à baixa qualidade do ar, a fim de prover uma estimativa da magnitude do aumento do problema devido ao aumento de pessoas expostas nas regiões mais afetadas. Essa informação é útil para fins de planejamento e estruturação dos sistemas de saúde para se adequar à possível demanda de serviços.

\section{DADOS DE FOCOS DE CALOR}

Os dados de focos de calor desta análise foram adquiridos na Plataforma Fire Information for Resource Management System (Firms/ Nasa) ${ }^{\mathbf{2 6}}$. Os dados de focos de calor têm uma atualização a cada três horas, e apresentam uma série histórica de dados, iniciada em 2002. Para esta pesquisa, utilizaram-se os dados do sensor Modis, a bordo do satélite Aqua, de 2003 a 2018. Os dados foram filtrados para um nível de confiança acima de $30 \%$, e, em seguida, agregados em uma grade matricial, contendo o acumulado de focos anuais.

\section{Avaliação da situação atual - agosto de 2019}

Após essa análise do período 2003-2018, adentra-se no estudo de caso dos impactos das queimadas e incêndios florestais na saúde pública acreana em 2019. Para tanto, consideraram-se os sensores de qualidade do ar disponíveis na plataforma de monitoramento PurpleAir ${ }^{15}$, com os limiares críticos de atenção à saúde humana. Essa análise foi complementada pela pesquisa documental nos meios de comunicação e pela observação participante em um grupo on-line de pessoas que lidam com o tema de gestão de riscos de desastres na região. Por meio da observação participante, um dos autores deste estudo tem acompanhado como as relações entre diferentes atores têm sido mediadas pela troca de dados e informações. No presente artigo, sistematizaram-se alguns desses dados de acordo com os tipos de dados e informações trocados. Os nomes e as instituições dos participantes foram omitidos, uma vez que o foco do artigo está nas práticas em torno dos dados e informações.

\section{Resultados e discussão}

\section{Diagnóstico dos registros de ocorrências de incêndios florestais e de portarias de SE e ECP no Sinpdec}

A primeira análise refere-se a uma avaliação do número de registros de ocorrências associadas às diferentes tipologias de incêndios, segundo as definições da Cobrade, entre 2000 e agosto de 2019. Nesse período, o S2ID computou 991 registros de ocorrências de incêndios em geral, dos quais 14 foram excluídos da base por se enquadrarem na categoria 'registro excluído'. Assim, dos 977 registros 
efetivamente incluídos, 674 (69\%) foram de incêndios florestais, sendo que 345 (35,3\% do total de registros de incêndios em geral) se referiram a incêndios florestais em áreas não protegidas, com reflexos na qualidade do ar. Das 13 unidades federativas que registraram essa tipologia, o estado do Rio de Janeiro apresentou o maior número de registros, com 108 ocorrências (31,3\% do total de registros de incêndios florestais em áreas não protegidas), seguido por São Paulo (60 registros), Espírito Santo (56 registros) e Pará (50 registros) (gráfico 1). O estado do Acre não apresentou nenhum registro dessa tipologia no S2ID para o período analisado. No que se refere à tipologia 'Incêndios em Parques, Áreas de Proteção Ambiental e Áreas de Preservação Permanente Nacionais, Estaduais ou Municipais', foram 329 (33,6\% do total) registros no período analisado, distribuídos em 22 unidades federativas. Nessa tipologia, o estado da Bahia foi o que apresentou o maior número de registros, 106 ocorrências (32,2\%), seguido por São Paulo (74), Mato Grosso do Sul (21) e Tocantins (20). O estado do Acre apresentou 10 registros de municípios para essa tipologia, todos de setembro de 2005.

Gráfico 1. Registros de ocorrências de incêndios florestais, em áreas protegidas e não protegidas, e portarias de Situação de Emergência (SE) e de Estado de Calamidade Pública (ECP), no período 2000 a 23 de agosto de 2019



Fonte: Elaboração própria.

Não protegidas = Incêndios em áreas não protegidas, com reflexos na qualidade do ar (Cobrade 1.4.1.3.2);

Protegidas = Incêndios em Parques, Áreas de Proteção Ambiental e Áreas de Preservação Permanente Nacionais, Estaduais ou Municipais (Cobrade 1.4.1.3.1);

Incêndios florestais e SE/ECP = Incêndios florestais (em áreas não protegidas - Cobrade 1.4.1.3.2 e protegidas - Cobrade 1.4.1.3.1) e portarias de (SE) e de Estado de Calamidade Pública (ECP) relacionadas. 
Se há danos e perdas que excedem a capacidade local de fazer frente à situação, ou seja, um desastre, pode-se recorrer a medidas de governo de exceção, declarando-se SE ou ECP. O município ou o ente estadual pode solicitar ao governo federal - no caso, a Secretaria Nacional de Proteção e Defesa Civil - a declaração de SE ou ECP, mas cabe ao ente federal o reconhecimento ou não dessa situação excepcional, a qual implica ter mecanismos para agilizar alguns trâmites burocráticos, como, por exemplo, utilização extra de recursos materiais e humanos para auxiliar as brigadas no combate aos incêndios florestais.

Do total de 345 registros de incêndios florestais em áreas não protegidas, com reflexos na qualidade do ar, somente 1 foi reconhecido como SE, no município de Cláudia, Mato Grosso, com data de 25 de setembro de 2017. Do conjunto de 329 registros de 'Incêndios em Parques, Áreas de Proteção Ambiental e Áreas de Preservação Permanente Nacionais, Estaduais ou Municipais', 33 foram reconhecidas (pouco mais de 10\%), sendo que, desse universo de portarias de SE ou ECP, 20 se referiram a municípios do Tocantins, no ano de 2010, e outras 6 portarias reconhecidas a municípios de Roraima, no ano de 2003. É interessante notar o contraste que existe entre o número de ECP ante os resultados de estudos da comunidade científica que avaliam impactos de queimadas e incêndios florestais na Amazônia. Por exemplo, Smith et al. quantificaram um aumento entre $1.2 \% \mathrm{e}$ $267 \%$ no número de hospitalizações de crianças com menos de cinco anos em municípios da Amazônia expostos a seca durante o ano de 2005, primariamente devido à poluição atmosférica advinda de queimadas e incêndios florestais ${ }^{27}$. Os autores quantificaram que o aumento em hospitalizações foi entre 1.3\% e $180.8 \%$ - em comparação com uma média histórica de 10 anos - em 77 (31.3\%) dos municípios da Amazônia Legal afetados pela seca de 2005, sendo que o maior valor de aumento ocorreu no município de Capixaba, no estado do Acre.
Historicamente, o Acre tem vivenciado eventos de queimadas e incêndios florestais com impactos na saúde pública. Em 22 de setembro de 1998, o então Secretário Especial de Políticas Regionais do Ministério do Planejamento e Orçamento, considerando as informações do Departamento de Defesa Civil e do Instituto Brasileiro do Meio Ambiente e dos Recursos Naturais Renováveis (Ibama), declarou, "em virtude do risco iminente de incêndio florestal, a situação de emergência [...] em Bujari, Porto Acre e Sena Madureira, no Estado do Acre"28. Em 21 de setembro de 2005, o governo estadual emitiu o Decreto $n^{\circ}$ 12.849, que declarava situação de emergência em áreas de 12 municípios acreanos "afetadas por incêndios florestais e poluição decorrente das queimadas" 29. Estima-se que mais de 400 mil pessoas foram afetadas por poluição atmosférica originada dos incêndios florestais e que o estado do Acre teve uma perda direta de mais de US\$ 50 milhões ${ }^{30}$. Apesar de após esse período não se encontrarem mais portarias, decretos e/ ou outros documentos reportando impactos em decorrência de queimadas e incêndios florestais no estado do Acre, estudos científicos relatam que, em 2010, o estado sofreu novamente uma grande seca com subsequentes grandes incêndios florestais ${ }^{31}$, tendo uma perda econômica naquele ano da ordem de US\$243.36 \pm 85.05 milhões ${ }^{32}$. No campo da saúde pública, o Ministério da Saúde, por meio do Sistema Nacional de Vigilância em Saúde, também não publicou, em seus relatórios de Situação-Acre para os anos de 2005 e 2006, dados e informações sobre impactos das queimadas e incêndios florestais. No relatório de situação de 2006, menciona que o Sistema de Vigilância em Saúde participou, juntamente com as secretarias estadual e municipal de saúde, de "investigações de surto [...] doença respiratória associada à poluição atmosférica, em Rio Branco, em setembro de 2005"33,34.

No último relatório disponível, do 
ano de $2011^{35}$, há menção à importância da 'Vigilância em Saúde de Populações Expostas a Poluentes Atmosféricos', definindo do que se trata esse tipo de vigilância, sua justificativa e os impactos potenciais à saúde, grupos mais vulneráveis (idosos e crianças) e formas de monitoramento (menção aos focos de calor):

A Vigilância em Saúde de Populações Expostas a Poluentes Atmosféricos busca a identificação das populações expostas e a gestão e organização dos serviços de vigilância e atenção à saúde, visto que a exposição humana a poluentes atmosféricos, em curto ou longo prazo, pode provocar impactos à saúde como o surgimento de agravos respiratórios, oculares e cardiovasculares ou o agravamento de doenças preexistentes, especialmente em crianças e idosos [...] As queimadas favorecem intensa produção de poluentes atmosféricos, entre os quais o material particulado com diâmetro igual ou menor a 2,5 $\mu \mathrm{m}$ (PM 2,5) que é considerado um dos indicadores de monitoramento e apresenta-se como fator de risco para doenças respiratórias, aumentando a procura por atendimentos médicos. Observa-se que o pico de queimadas ocorre entre os meses de julho a novembro. Nesse período, as ações de vigilância em saúde para as populações mais vulneráveis à poluição atmosférica devem ser intensificadas ${ }^{35}$.

Entre julho e agosto de 2019, pouco antes e/ou no esteio da crise diplomática internacional mobilizada em torno das queimadas e incêndios florestais no País, algumas unidades federativas da Amazônia Legal decretaram SE ou elaboraram outros decretos com força-de-lei para atuarem na crise das queimadas e incêndios florestais. No estado do Acre, foco deste artigo, dois decretos estaduais foram emitidos, o 'Estado de Alerta Ambiental' (Decreto $\mathrm{n}^{0} 3.776$ ), no dia 15 de agosto, e a SE uma semana após (Decreto $n^{\circ} 3.869$ ). A seguir, avalia-se a problemática da situação no estado do Acre.

\section{Exposição da população à ocorrência de queimadas e incêndios florestais e baixa qualidade do ar}

Entre os anos de 2000 e 2015, observou-se um aumento populacional tanto na porção sudeste do quanto na noroeste do Acre (figura 2). É interessante observar que o número de pessoas expostas a queimadas e incêndios florestais diminuiu a partir do ano de 2005 , atingindo um mínimo no ano de 2012; e, a partir de então, há um aumento até o ano de 2018 (figura 2). Além disso, apesar de nas áreas com maiores concentrações populacionais não haver uma grande variação do número de pessoas expostas a queimadas e incêndios florestais em todo o período, observa-se que, para as áreas menos populadas (células com até 50 pessoas por $\mathrm{km}^{2}$ ), há um aumento progressivo do número de observações de focos de calor, sugerindo um maior número de pessoas expostas a eventos de queimadas e incêndios florestais. O detalhe destacado no retângulo pontilhado no item $b$ da figura 2 refere-se ao período recente, a partir de 2012, em que se observa um aumento na ocorrência de eventos de queimadas e incêndios em áreas com até 50 pessoas por $\mathrm{km}^{2}$. 
Figura 2. a) Diferença da contagem populacional entre 2015 e 2000. b) Exposição da população, estratificada por classes de número de pessoas por km², a eventos de queimadas e incêndios florestais, para o período de 2003 a 2018

\section{Grade populacional} Diferença entre 2015 e 2000

Diminuição da população (-1)

Aumento baixo da população (0-0.2)

Aumento moderado da população (0.2-1)

Aumento alto da população (1-2)

Aumento muito alto da população (2-10)

a
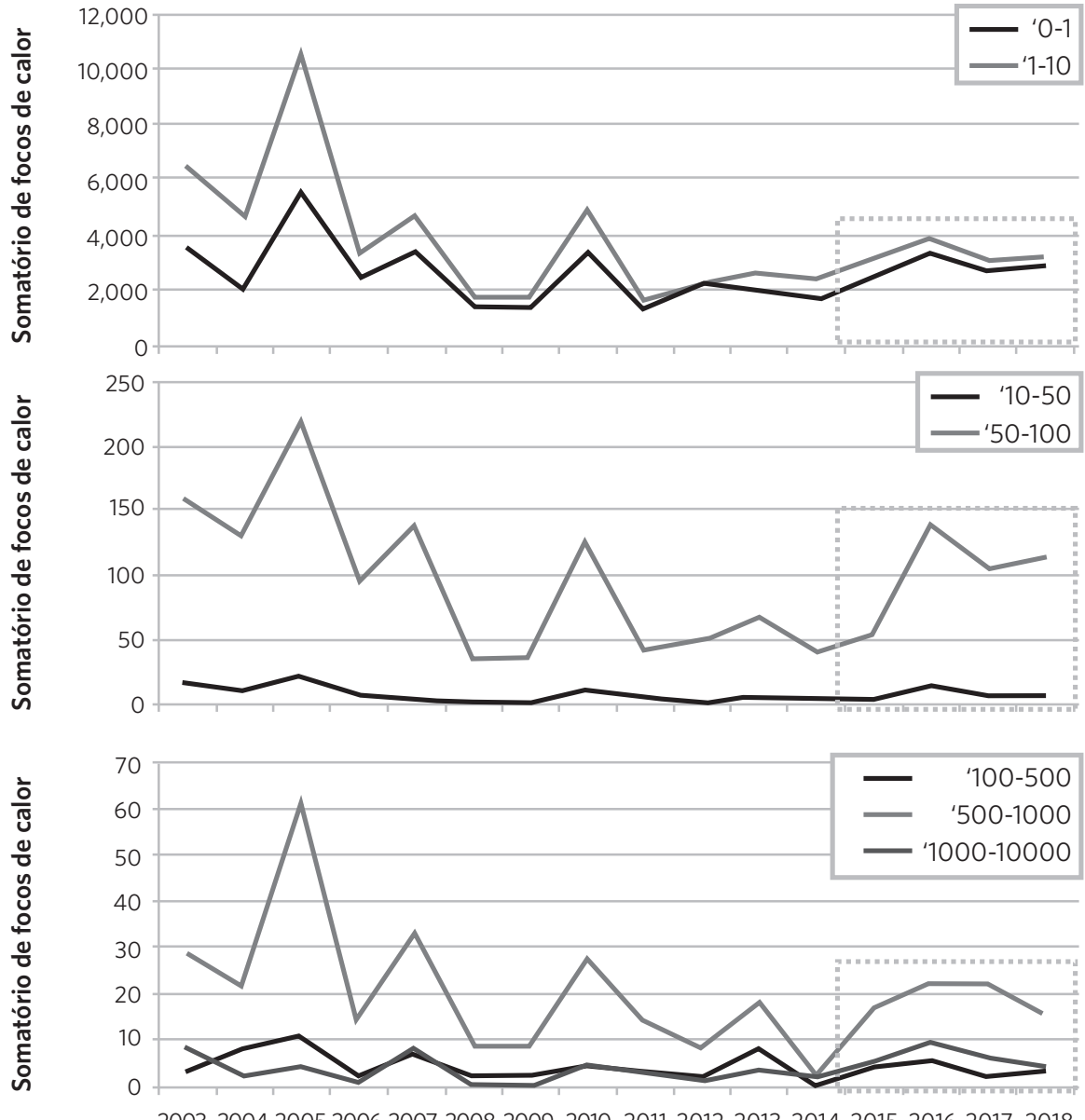

b

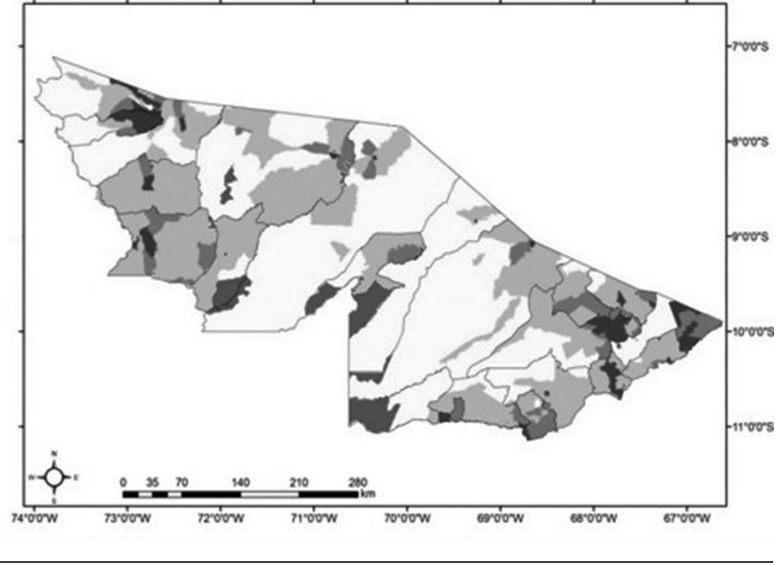

$-10$ 
Entre os anos de 1998 e 2016, os locais onde observamos um aumento populacional correspondem às áreas em que houve uma maior recorrência da baixa qualidade do ar, sendo que a região sudeste do estado é a mais fortemente afetada (figura 3a). Além disso, entre os anos de 1998 e 2016, observou-se um aumento de mais de $80 \mathrm{mil}$ pessoas em áreas onde há predomínio da baixa qualidade do ar, e um aumento de 10 mil a 40 mil pessoas em regiões onde, em cerca de $50 \%$ do tempo e $11 \%$ do período, elas ficaram expostas à baixa qualidade do ar respectivamente (figura $3 b$ ).

Figura 3. a) Número de anos com alta concentração de materiais particulados menores do que 2,5 micrômetros (PM 2,5). Uma recorrência de 18 vezes significa que no período estudado, prevaleceu, por ano, uma alta concentração PM 2,5. b) Aumento do número de pessoas, entre 2000 a 2015, expostas à recorrência de baixa qualidade do ar no estado do Acre

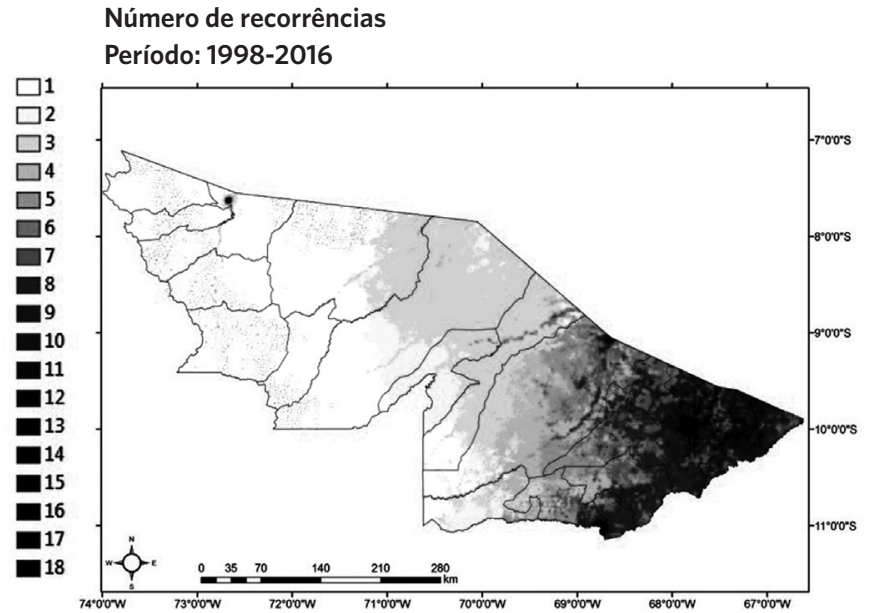

a

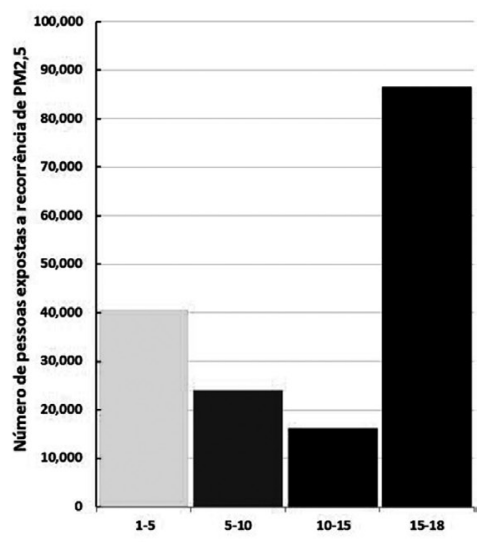

b

Fonte: Elaboração própria.

\section{Avaliação da situação atual - agosto de 2019}

A vivência compartilhada de inundações na Bacia do Rio Acre fez com que alguns gestores de emergência e cientistas da região conhecida como MAP (Madre de Dios-Peru, Acre-Brasil e Pando-Bolívia) se organizassem para melhorar sua capacidade de preparação diante de desastres, o que tem ocorrido por meio da realização de fóruns, workshops e troca contínua de dados e informações mediante redes sociais, como aplicativos de mensagens. Por intermédio da observação participante, um dos autores deste estudo tem participado dessa rede de colaboração e analisa como se dão as trocas de dados e informações. Na estação chuvosa, os dados e informações trocados se referem à previsão climatológica, previsão do tempo, precipitação acumulada, nível dos rios e dados de ocorrências. Na estação seca, além do compartilhamento dos dados mencionados anteriormente, também se tem feito uso de uma rede de sensores de qualidade do ar com dados disponibilizados na plataforma on-line PurpleAir. Brown e colaboradores relatam como essa rede foi implementada voluntariamente na região MAP a partir de 
novembro de 2017, com dois sensores instalados em duas universidades no Acre (em Rio Branco e Cruzeiro do Sul), um na sede de uma Organização Não Governamental (ONG) em Porto Maldonado (Peru) e outro em uma sede de outra ONG em Cobija (Bolívia) ${ }^{\mathbf{1 5}}$. Essa rede foi expandida. No dia 30 de abril de 2019, o Ministério Público do Estado do Acre inaugurou uma unidade do sistema de monitoramento da qualidade do ar para acompanhar as medições de 30 equipamentos instalados em todos os municípios acreanos, em parceria com diferentes setores, como Saúde, Meio Ambiente, Educação e Defesa Civil ${ }^{36}$.

As queimadas e os incêndios florestais ocorridos em agosto de 2019 mobilizaram algumas trocas de dados e informações sobre qualidade do ar. Em um dos grupos de aplicativos de mensagens analisado, um primeiro alerta informal é dado na tarde do dia 6 de agosto:

A situação de qualidade do ar está problemática no Acre, pelo menos. Seguem dados que mostram altas concentrações de fumaça em Assis Brasil durante as últimas noites. Pessoal de Inapari [Peru] e Assis Brasil [Acre] podem confirmar? (M1).

O alerta informal é baseado em um primeiro limiar que é compartilhado pela imagem, capturada pela tela do computador, dos dados do sensor (figura 4). A mensagem é complementada por uma informação de potencial impacto à saúde humana: "Nestas concentrações podem provocar problemas respiratórios" (M2). Algumas horas depois, outro participante responde: "A situação esses dias está insuportável [...]! Ar totalmente comprometido! Muita fumaça e poeira! [...].” (M3). Quase 11 horas depois do primeiro alerta, envia-se um novo panorama do monitoramento dessas duas cidades: "Melhorou em Assis [Acre] e Inapari [Peru] de péssimo para ruim” (M4); seguido de outra imagem capturada pelo celular.

Na manhã do dia seguinte (7 de agosto de 2019), novos alertas: "A situação em Assis Brasil [AC] está péssima. E Inapari [Peru]" (M5). Ainda, complementa com informações sobre a situação na capital acreana: "A situação em Rio Branco está péssima" (M6). No período de $1^{\circ}$ a 7 de agosto, o sensor de qualidade do ar demonstrava o aumento abrupto do material particulado, acima de 301 PM 2,5, que apresenta o seguinte alerta: 'Avisos de saúde de condições de emergência se expostos por 24 horas. É provável que toda a população seja afetada'. Naquele período, impactos na saúde pública já estavam sendo registrados pela Vigilância em Saúde da Secretaria Municipal de Rio Branco, que apontou quase 30 mil casos de infecções respiratórias registrados até 10 de agosto em unidades de saúde do município ${ }^{35}$. 
Figura 4. Dados de qualidade do ar em Assis Brasil, Acre, no dia 6 de agosto de 2019

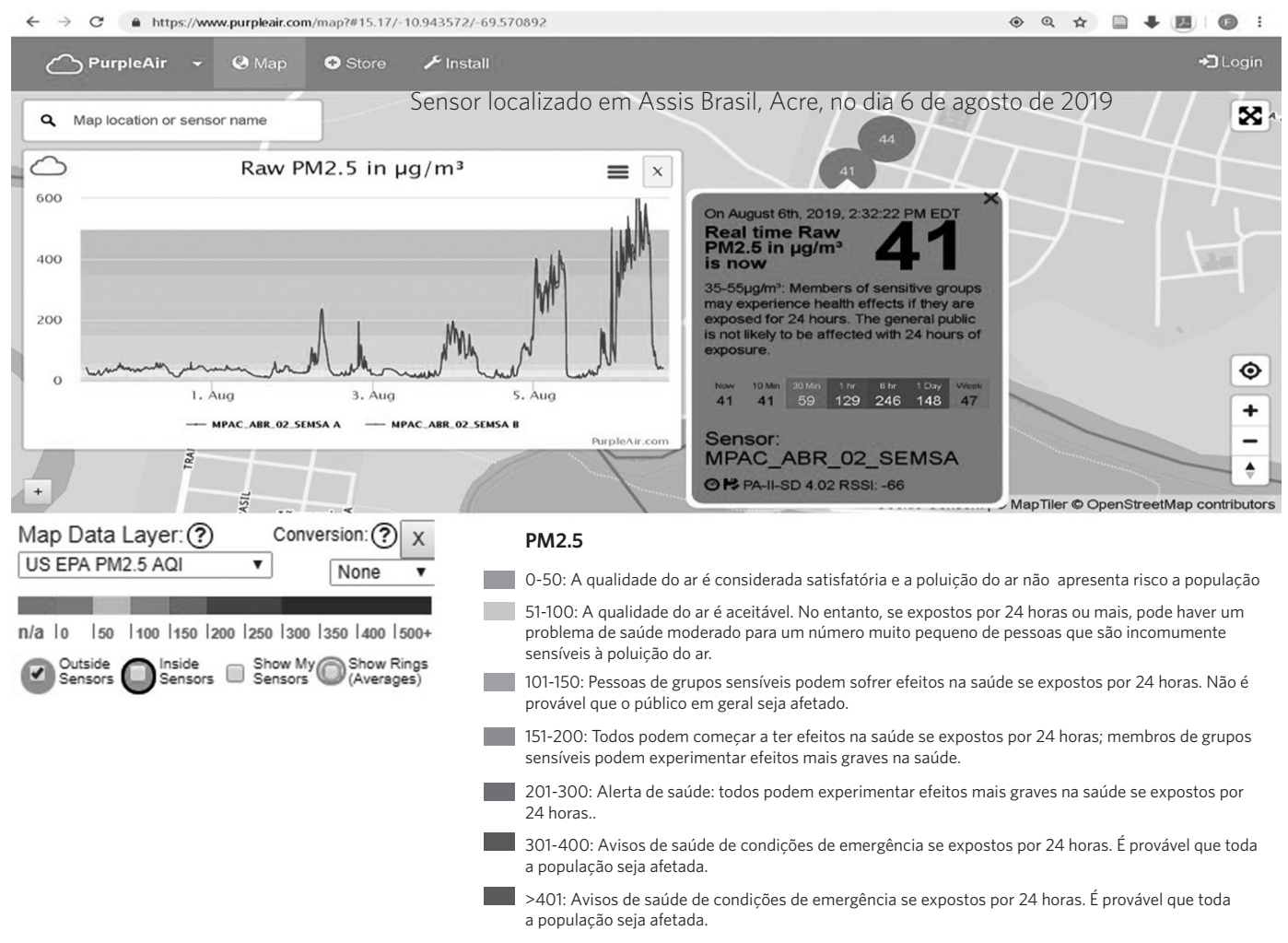

Fonte: Elaboração própria baseada no gráfico de níveis de concentração de PM2.5 da PurpleAir37.

Nota: É interessante notar que, desde o dia 2 de agosto, os dados já apontam para horários com nível de PM2.5 maiores que 200 sendo considerados críticos.

\section{Conclusões e recomendações}

Diversos estudos científicos têm reportado os impactos de queimadas e as doenças respiratórias em diferentes grupos sociais e regiões do Brasil38-41. Todavia o registro oficial de ocorrências e/ou de desastres associados a incêndios florestais está subdimensionado pelo Sinpdec, sobretudo no S2ID. As análises apresentadas neste estudo sugerem que existe um negligenciamento em registrar-se, no S2ID, ocorrências de incêndios florestais e/ou situações de emergência e calamidade pública associados à baixa qualidade do ar, oriundos de queimadas e incêndios florestais, principalmente na região norte do País, onde há maior ocorrência desses eventos. Alguns estudos sobre capacidades institucionais de defesa civil apontam as limitações e dificuldades operacionais encontradas, como a falta de veículos que permitam ir a campo, monitorar e registrar ocorrências, falta de computadores e dificuldade na organização de bancos de dados, rotatividade de profissionais, baixo orçamento $\mathbf{4 2 , 4 3}$.

No âmbito da gestão de risco de desastres associados a incêndios florestais, são essenciais pesquisas científicas para compreender as barreiras e insuficiências no registro de dados de incêndios pelo Sinpdec. São também fundamentais pesquisas que permitam combinar bases de dados a fim de diminuir as lacunas de informação, geração e disseminação do conhecimento. Os resultados parciais deste artigo podem servir como um ponto de partida para aprimorar o planejamento das ações de 
gestão de risco de desastres associados a incêndios florestais, uma vez que fornecem um diagnóstico sobre as mudanças na exposição da população à fumaça gerada por incêndios florestais. Por meio dos resultados, podem-se aprimorar os planos de contingência e resposta, assim como organizar campanhas de prevenção em localidades com recorrência de baixa qualidade do ar.

$\mathrm{O}$ aumento do número de pessoas em áreas onde há prevalência de baixa qualidade do ar no estado do Acre foi significativo, somando-se, no total, mais de 80 mil pessoas. Neste estudo, não foi realizada uma análise da capacidade da rede estadual e municipal de saúde do estado do Acre em atender a população. No entanto, devido à situação crítica da ocorrência de queimadas e incêndios florestais reportados durante a crise do fogo, em agosto de 2019, entende-se que há possibilidade desse quadro ser considerado um desastre. Outro ponto importante refere-se à capacidade de monitoramento. No estado do Acre, há uma rede adequada de monitoramento da qualidade do ar; no entanto, nos países vizinhos, tal subsídio não é instalado. Assim, a rede de proteção voluntária criada pela sociedade na região MAP demonstra que o compartilhamento de informações referentes à qualidade do ar pode ser feito; e a realidade do Acre é também refletida regionalmente, em Pando, na Bolívia, e em Madre de Dios, no Peru.

Trabalhos futuros deverão investigar a relação local entre os dados dos sensores de qualidade do ar com o número de internações, visando estabelecer limiares que permitirão ao sistema público de saúde planejar ações de resposta à situação de crise. Além da análise de exposição das pessoas, também será importante a realização de pesquisas que analisem as dimensões de vulnerabilidade a incêndios florestais.

\section{Agradecimentos}

Os autores deste artigo agradecem a InterAmerican Institute for Global Change Research (IAI), Fundação de Amparo à Pesquisa do Estado de São Paulo (Fapesp) e Conselho Nacional de Desenvolvimento Científico e Tecnológico (CNPq), pelo financiamento do projeto de pesquisa. Os autores também agradecem aos produtos de Land, Atmosphere Near real-time Capability for EOS do Sistema Lance, desenvolvido pela Nasa's Earth Science Data e Information System (Esdis) com financiamento da Nasa Headquarters.

\section{Colaboradores}

Anderson L (0000-0001-9545-5136)* e Marchezini V (0000-0002-1974-0960)* contribuíram igualmente para a concepção e planejamento do artigo, análise e interpretação dos dados. 


\section{Referências}

1. Li X, Jin L, Kan H. Air pollution: a global problem needs local fixes. Nature [internet]. 2019 [acesso em 2019 ago 1]; (570):437-439. Disponível em: https:// www.nature.com/articles/d41586-019-01960-7.

2. UNDRR Terminology: HAZARD [internet]. [acesso em 2019 set 19]. Disponível em: https://www.undrr. org/terminology/hazard.

3. Gonçalves KS, Castro HA, Hacon SS. As queimadas na região amazônica e o adoecimento respiratório. Ciênc. Saúde Colet. [internet]. 2012 [acesso em 2019 ago 1]; 17(6):1523-1532. Disponível em: https://dx.doi. org/10.1590/S1413-81232012000600016.

4. Rodrigues PCO, Ignotti E, Hacon SS. Distribuição espaço-temporal das queimadas e internações por doenças respiratórias em menores de cinco anos de idade em Rondônia, 2001 a 2010. Epid. Serv. Saúde [internet]. 2013 [acesso em 2017 jan 2]; 22(3):455464. Disponível em: https://dx.doi.org/10.5123/ S1679-49742013000300010.

5. Luana MMS, Castro FR, Bastos DMRF, et al. Impactos das queimadas sobre a saúde da população humana na Amazônia Maranhense. Revista de Pesquisa em Saúde [internet]. 2016 [acesso em 2019 ago 1]; 17(3):141-146. Disponível em: http://www.periodicoseletronicos.ufma.br/index.php/revistahuufma/article/view/5400.

6. Miranda RM, Fatima MA, Fornaro A, et al. Poluição do ar urbano: um levantamento representativo das concentrações de massa do PM 2,5 em seis cidades brasileiras. Air Qual Atmos Health [internet]. 2012 [acesso em 2019 ago 1]; (5):63. Disponível em: https://doi.org/10.1007/s11869-010-0124-1.

7. Reddington CL, Butt EW, Ridley DA, et al. Air quality and human health improvements from reductions in deforestation-related fire in Brazil. Nat. Geosc. [internet]. 2015 [acesso em 2017 jan 2]; (8):768-771. Disponível em: https://www.researchgate.net/publication/282662372_Air_quality_and_human_he- alth_improvements_from_reductions_in_deforestation-related_fire_in_Brazil.

8. Cassou E. Field Burning. Agricultural Pollution [internet]. 2018 [acesso em 2019 ago 1]; 1-7. Disponível em: https://openknowledge.worldbank.org/handle/10986/29504.

9. Ramdhan DH, Rizky ZP, Atmajaya H, et al. Particu-late Matter and Subjective Respiratory Health Effect Measurements in Palembang during For-est Fire Episode in October 2015 [internet]. 2018 [acesso em 2020 fev 1]; 4(4):355-61. Disponível em: https://scholar.ui.ac.id/en/publications/particulate-matter-and-subjective-respiratory-health-effect-measu.

10. Barbosa RI, Fearnside PM. Incêndios na Amazônia brasileira: Estimativa da emissão de gases do efeito estufa pela queima de diferentes ecossistemas de Roraima na passagem do evento "El Niño" (1997/98). Acta Amazonica. 1999; 29(4):513-534.

11. Aragão LEOC, Anderson LO, Fonseca MG, et al. 21st Century drought-related fires counteract the decline of Amazon deforestation carbon emissions. Nature Communications. 2018 [acesso em 2020 jun 19]; 9(536). Disponível em: https://www.nature.com/ articles/s41467-017-02771-y.

12. Anderson LO, Aragão LEOC, Gloor M, et al. Disentangling the contribution of multiple land covers to fire-mediated carbon emission in Amazonia during the 2010 drought. Global biogeoch. cycles. 2010; (28):1739-1753.

13. Aragão LEOC, Malhi Y, Barbier N, et al. Interactions between rainfall, deforestation and fires during recent years in the Brazilian Amazonia. Philos. Trans. R. Soc. B. 2008; (363):1779-1785.

14. UNDRR Terminology: DISASTER [internet]. [acesso em 2019 set 19]. Disponível em: https://www.undrr.org/terminology/disaster. 
15. Brown IF, Duarte AF, Torres M, et al. Monitoramento de fumaça em tempo real mediante sensores de baixo custo instalados na Amazônia Sul Ocidental [internet]. In: Anais do $19^{\circ}$ Simpósio Brasileiro de Sensoriamento Remoto; Abri 14-17; Santos. Santos: Instituto Nacional de Pesquisas espaciais; 2019. [acesso em 2019 ago 28]. Disponível em: https:// proceedings.science/sbsr-2019/papers/monitoramento-de-fumaca-em-tempo-real-mediante-sensores-de-baixo-custo-instalados-na-amazonia-sul-ocidental.

16. Rodrigues M. Ação das Forças Armadas contra queimadas na Amazônia deve ser estendida até outubro, diz Mourão [internet]. G1. 2019 set 13. [acesso em 2019 out 28]. Disponível em: https://gl.globo. com/politica/noticia/2019/09/13/acao-das-forcas-armadas-contra-queimadas-na-amazonia-deve-ser-estendida-ate-outubro-diz-mourao.ghtml.

17. National Aeronautics and Space Administration (Nasa). Worldview [internet]. 2019 [acesso em 2019 ago 10]. Disponível em: https://worldview.earthdata.nasa.gov.

18. Silva IVM. Vulnerabilidade institucional do setor saúde a desastres no município de Nova Friburgo [dissertação]. Rio de Janeiro: Fundação Oswaldo Cruz; 2019. 159 p.

19. Chambers R. Vulnerability, coping and policy. IDS bulletin [internet]. 1989 [acesso em 2017 jan 2]; 20(2):1-7. Disponível em: https://onlinelibrary.wiley.com/doi/abs/10.1111/j.1759-5436.1989. mp20002001.x.

20. Wisner B, Gaillard JC, Kelman I. Framing disaster: Theories and stories seeking to understand hazards, vulnerability and risk. In: Wisner B, Gaillard JC, Kelman I. The Routledge handbook of hazards and disaster risk reduction. Londres: Routledge; 2012. p. 18-34.

21. Basher R. Global early warning systems for natural hazards: systematic and people centered. Philosophical Transactions A [internet]. 2006 [acesso em
2017 jan 2]; 364(1845):2167-2182. Disponível em: https://www.ncbi.nlm.nih.gov/pubmed/16844654.

22. Anderson LO, Marchezini V, Morello TF, et al. Modelo conceitual de sistema de alerta e de gestão de riscos e desastres associados a incêndios florestais e desafios para políticas públicas no Brasil. Territorium [internet] 2019 [acesso em 2019 jul 23]; (26):43-61. Disponível em: https://impactum-journals.uc.pt/territorium/article/view/6427.

23. Brasil. Ministério da Integração Nacional. Manual para decretação de Situação de Emergência ou Estado de Calamidade Pública [internet]. Brasília, DF: MS; 2007. [acesso em 2017 jan 2]. Disponível em: https://defesacivil.es.gov.br/Media/defesacivil/ Publicacoes/Manual\%20para\%20Decretacao\%20 de\%20Situacao\%20de\%20Emergencia\%20ou\%20 de\%20Estado\%20de\%20Calamidade\%20Publica\%20-\%20Vol.\%20I.pdf.

24. Center for International Earth Science Information Network. Gridded Population of the World, Version 4 (GPWv4): Population Count, Revision 11 [internet]. Palisades: Nasa; 2018. [acesso em 2019 jul 23]. Disponível em: https://doi.org/10.7927/ H4JW8BX5.

25. Van Donkelaar A, Martin RV, Brauer M, et al. Global Annual PM2.5 Grids from Modis, MISR and SeaWiFS Aerosol Optical Depth (AOD) with GWR, 1998-2016 [internet]. Palisades: Nasa; 2018. [acesso em 2019 out 23]. Disponível em: https://doi. org/10.7927/H4ZK5DQS.

26. Modis Collection 6 NRT Hotspot / Active Fire Detections MCD14DL [internet]. 2019 [acesso em 2019 set 23]. Disponível em: https://earthdata.nasa.gov/ firms.

27. Smith L, Aragão L, Sabel C, et al. Drought impacts on children's respiratory health in the Brazilian Amazon. Sci Rep [internet]. 2015 [acesso em 2019 jul 23]; 4(3726)1-8. Disponível em: https://doi.org/10.1038/ srep03726. 
28. Brasil. Ministério do Planejamento e Orçamento. Portaria $\mathrm{n}^{\mathrm{0}} 71$, de 22 de setembro de 1998 [internet]. Declara situação de emergência nos Municípios do Nordeste, Estados de Minas Gerais e Espírito Santo, atingidos por estiagem. Diário Oficial da União. 23 Set 1998. [acesso em 2019 jul 23]. Disponível em: https://cdn.labtrans.ufsc.br/s2id/AC/ AC-P-1200138-14131-19980708.pdf.

29. Acre. Decreto $\mathrm{n}^{\circ} 12849$, de 21 de setembro de 2005 [internet]. 2005. [acesso em 2019 ago 1]. Disponível em: https://cdn.labtrans.ufsc.br/s2id/AC/ACD-1200013-14131-20050901.pdf.

30. Brown IF, Schroeder W, Setzer A, et al. Monitoring fires in southwestern Amazonia rain forests. EOS [internet]. 2006 [acesso em 2017 jan 2]; 87(26):253264. Disponível em: https://agupubs.onlinelibrary. wiley.com/doi/epdf/10.1029/2006EO260001.

31. Alverga DPP, Brown IF, Galvão AS, et al. Análise exploratória das cicatrizes de incêndios florestais de 2010 no estado do Acre, Brasil [internet]. In: Anais $16^{\circ}$ Simpósio Brasileiro de Sensoriamento Remoto; 2013 Abr 13-18, Foz do Iguaçu. Foz do Iguaçu: INPE; 2013. [acesso em 2019 jul 1]. Disponível em: http://marte2.sid.inpe.br/col/dpi.inpe. br/marte2/2013/05.29.00.29.15/doc/p1149.pdf.

32. Campanharo WA, Lopes AP, Anderson LO, et al. Translating Fire Impacts in Southwestern Amazonia into Economic Costs. Remote Sensing, [internet]. 2019 [acesso em 2019 ago 29]; 11(764):122. Disponível em: https://pdfs.semanticscholar. org/9ea0/cea03beealdac4cb945cdf5d3daa9f8eade5.pdf?_ga=2.269110706.236901783.1567163729961004765.1565807316.

33. Brasil. Ministério da Saúde. Relatório de Situação Acre 2005 [internet]. Brasília, DF: MS; 2005. [acesso em 2019 ago 29]. Disponível em: http://bvsms. saude.gov.br/bvs/publicacoes/acl.pdf.

34. Brasil. Ministério da Saúde. Relatório de Situação - Acre 2006 [internet]. Brasília, DF: MS; 2006. [acesso em 2019 ago 29]. Disponível em: http:// bvsms.saude.gov.br/bvs/publicacoes/relatorio_ snvs_ac_2ed\%5B1\%5D.pdf.

35. Brasil. Ministério da Saúde. Relatório de Situação Acre 2011 [internet]. Brasília, DF: MS; 2011. [acesso em 2019 ago 29]. Disponível em: http://bvsms. saude.gov.br/bvs/publicacoes/sistema_nacional_ vigilancia_saude_ac_5ed.pdf.

36. Melo AWF, Silva SS, Anderson LO, et al. Monitoramento da qualidade do ar em 2019 no Estado do Acre. Cruzeiro do Sul: UFAC, 2020. 28 p. [acesso em 2020 jun 19]. Disponível em: https://www.researchgate.net/publication/340540446_Monitoramento_da_qualidade_do_ar_em_2019_no_Estado_do_Acre.

37. PurpleAir: Real-time Air Quality Monitoring [internet]. [acesso em 20197 ago 7]. Disponível em: https://www2.purpleair.com/.

38. Melo Q. Rio Branco registra quase 30 mil casos de infecções respiratórias devido a queimadas [internet]. G1. 2019 ago 19. [acesso em 2019 ago 28]. Disponível em: https://gl.globo.com/ac/acre/noticia/2019/08/19/rio-branco-registra-quase-30-mil-casos-de-infeccoes-respiratorias-devido-a-queimadas.ghtml.

39. Marlier ME, DeFries R, Voulgarakis A, et al. El Nino and health risks from landscape fire emissions in southeast Asia. Nature Clim. Change. 2013; (3):131136.

40. Johnston FH, Henderson SB, Yang Chen JT, et al. Estimated Global Mortality Attributable to Smoke from Landscape Fires. Environ. Health Perspect. 2012; 120(5):695-701.

41. Jacobson LSV, Hacon SS, Castro HA, et al. Acute effects of particulate matter and black carbon from seasonal fires on peak expiratory flow of school children in the Brazilian Amazon. PLoS ONE. 2014; 9(8):e104177.

42. Londe LR, Soriano E, Coutinho MP. Capacidades 
das instituições municipais de Proteção e Defesa Civil no Brasil: desafios e perspectivas. Revista do Departamento de Geografia (USP). [internet]. 2015 [acesso em 2019 jul 24]; (30):77-95. Disponível em: http://www.revistas.usp.br/rdg/article/ view/98715/107757.

43. Dutra AS, Gonçalves RS. A atuação dos assistentes sociais nos órgãos municipais de Proteção e Defesa Civil. Em Pauta [internet]. 2012 [acesso em 2019 jul 24]; 37(14):106-125. Disponível em: https://www.e- -publicacoes.uerj.br/index.php/revista' empauta/ article/view/25388.

Recebido em 30/08/2019

Aprovado em 08/04/2020

Conflito de interesses: inexistente

Suporte financeiro: Inter-American Institute for Global Change Research (IAI), (Processo no SGP-HW 016). Fundação de Amparo à Pesquisa do Estado de São Paulo (Fapesp), (Processos no 2016/02018-2, 2018/06093-4, 19/05440-5). Conselho Nacional de Desenvolvimento Científico e Tecnológico (CNPq), (Processos no 442650/2018-3 e 309247/2016-0) 